\title{
Effective Notch Stress Method for Fatigue Evaluation of Welded Joints in a Steel Bridge Deck
}

\author{
Sim, Hyoung-Bo ${ }^{\dagger}$
}

\begin{abstract}
Effective notch stress, as an approach to evaluate the local stress at a notch (weld toe or root), is defined as the total stress assuming linear-elastic material behavior. This method can be effectively used to evaluate the fatigue performance of welded joints. In this study, finite element analysis results using the effective notch stress method were correlated with fatigue test results of rib-to-deck welded joints in a steel orthotropic bridge deck. Effective notch stress approach provided a good correlation with the crack pattern observed in the full-scale fatigue test. A higher effective notch stress at the critical weld toe than at the weld root was consistent with the dominant crack pattern observed at the weld toe during testing. The effective notch stress at the toe on the deck plate was about $80 \%$ higher than that on the rib; no cracks at the weld toe on the rib in the testing were observed. Maximum effective notch stress at the weld root occurred on the upper side of the root notch, which indicates that cracks are more likely to propagate into the deck plate, not into the weld metal. This is also consistent with the observed crack pattern in which the crack from the root propagated upward into the deck plate. No such crack pattern, propagating into the weld metal, was observed in the testing.
\end{abstract}

Key words : Effective notch stress, Fatigue crack, Finite element analysis, Welded joint, Steel bridge

\section{Introduction}

Effective (or imaginary) notch stress, as an approach to evaluate the local stress at a notch (weld toe or root), is defined as the total stress (for example, Von-Mises Stress) assuming linear-elastic material behavior. This approach has been extensively discussed by International Institute of Welding (IIW 2007), and it is documented in the IIW Recommendations (Miki 2006). The actual weld contour is replaced by an effective one in order to consider the statistical nature and scatter of weld shape parameters, as well as the non-linear material behavior at the notch. In this study, finite element analysis results using the effective notch stress method were correlated with fatigue test results to investigate its effectiveness in fatigue evaluation of welded joints in a steel orthotropic bridge deck.

\footnotetext{
$\dagger$ Corresponding author: Korea Railroad Research Institute E-mail : hbsim@krri.re.kr
}

\section{Fatigue Test}

\subsection{Orthotropic bridge deck}

An orthotropic steel deck, which is widely used for longand medium-span bridges, typically consists of thin steel plate stiffened by a series of closely spaced longitudinal ribs and transverse floor beams supporting the deck plate (see Fig. 1).

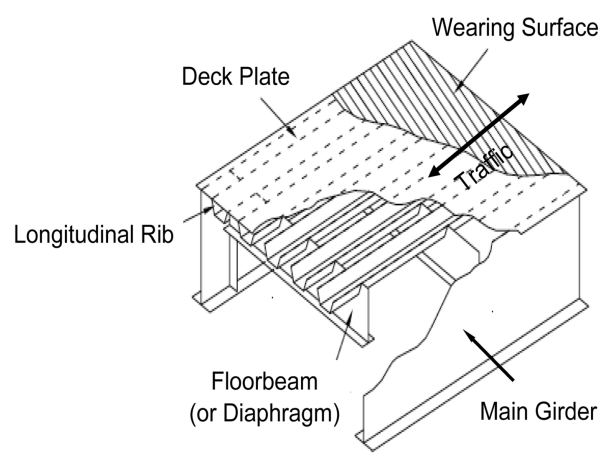

Fig. 1 Typical configuration of orthotropic deck (Troitsky 1987) 


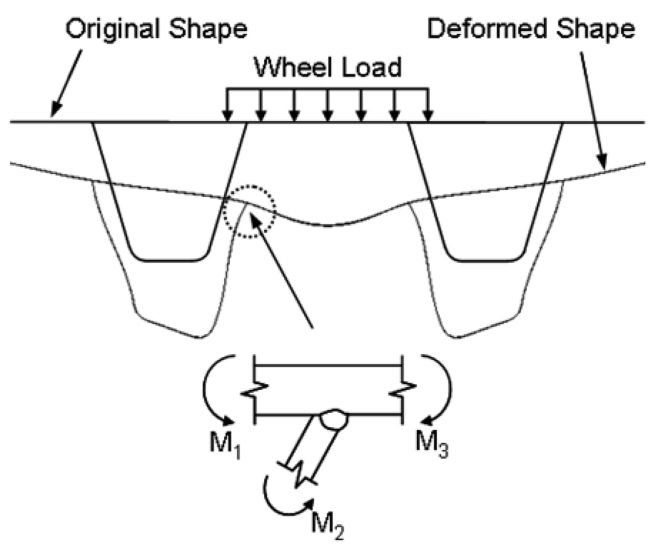

Fig. 2 Local deformation at rib-to-deck welded joint

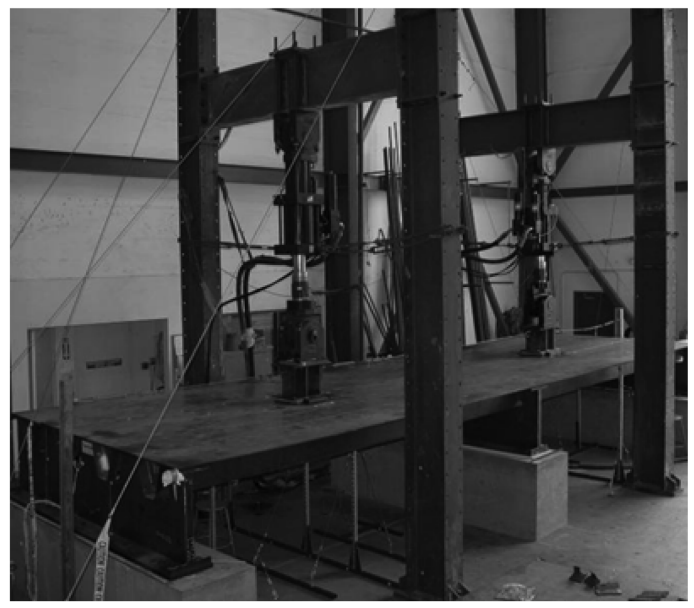

(a) Test setup

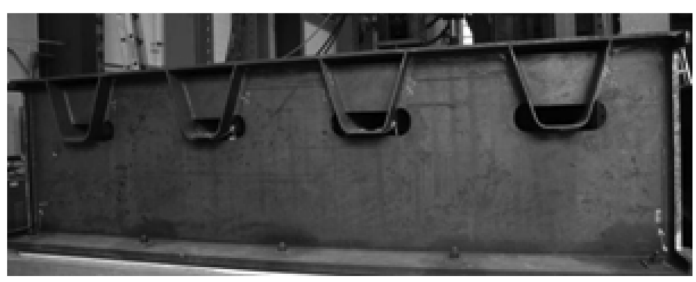

(b) Cross-sectional view at end diaphragm

Fig. 3 Fatigue test setup

Despite light weight and excellent structural characteristics of this deck system, orthotropic steel deck bridges have experienced a variety of fatigue problems. In particular, rib-todeck partial-joint-penetration (PJP) welded joints are prone to fatigue cracking because they are subjected to local secondary deformations (out-of-plane transverse bending moment) from the directly applied wheel loads, as shown in Fig. 2.

\subsection{Test condition}

Recently, six full-scale orthotropic deck specimens (10

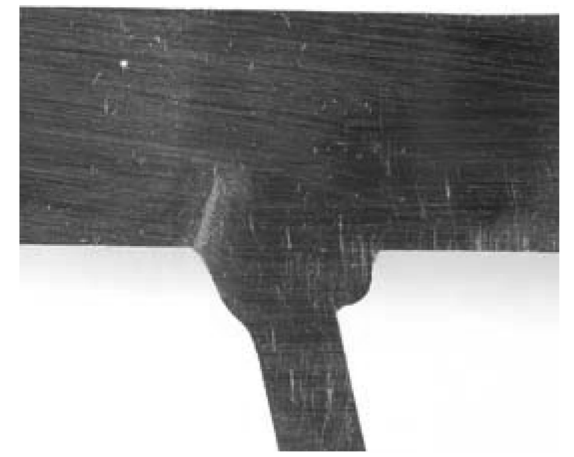

(a) Crack from weld toe

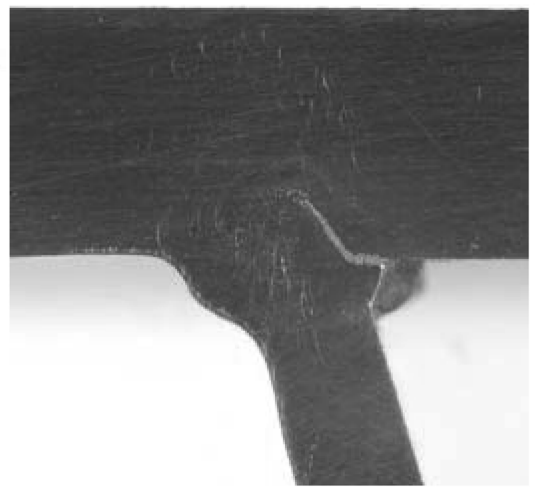

(b) Crack from weld root

Fig. 4 Fatigue cracks observed during testing

$\mathrm{m}$ long and $3 \mathrm{~m}$ wide) were tested at the University of California, San Diego to evaluate the fatigue performance at rib-to-deck welded joint (Sim and Uang 2007). ASTM A709 Grade 345 steel was used for the specimens. Each deck panel was composed of a 16-mm-thick deck plate and four 8-mm-thick ribs. Fig. 3 shows the test setup with cross-sectional view of the test specimen. An actuator was centered on each span, and the diaphragms of each specimen were supported by concrete blocks. The specimen was loaded using hydraulic actuators at midspan. The applied loads from the two actuators were out of phase to simulate the effect of a truck passage. The loads from each actuator at midspan were uniformly distributed through a spreader beam to the loading pads. The testing was conducted in a load-controlled mode with a loading frequency ranging from 4 to $6 \mathrm{~Hz}$.

\subsection{Summary of test results}

Fatigue test results showed that six cracks at rib-to-deck welded joint developed from the weld toe outside the closed rib, and only one crack developed at the weld root inside the closed rib. Based on the loading pattern applied and the limited database, it was indicated that the rib-to- 


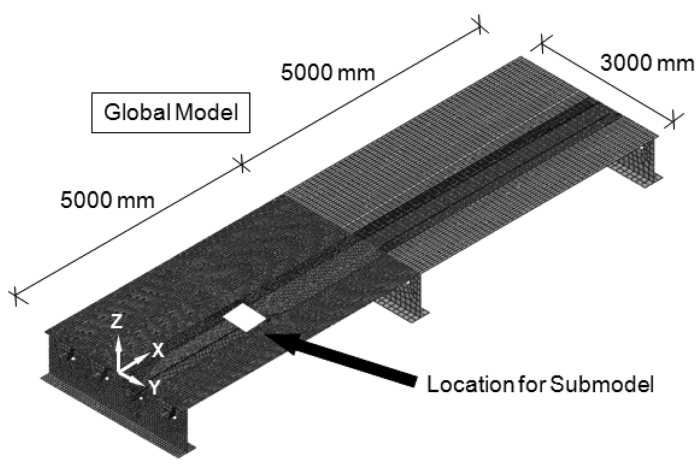

(a) Global model

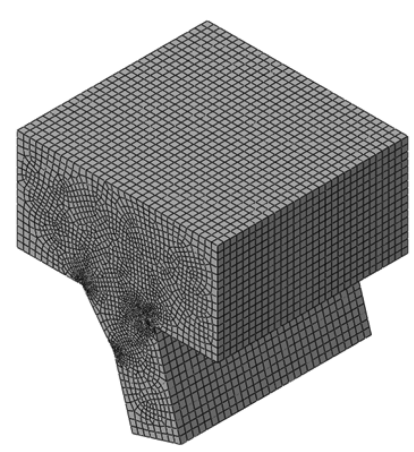

(b) Submodel

Fig. 5 Finite element models

deck PJP welds are more vulnerable to crack initiation from the weld toe than from the weld root.

Fig. 4 shows the crack patterns observed at the rib-to-deck welded joints by magnetic particle inspection after completion of testing. All seven cracks were developed within the deck plate and not within the rib wall, which indicates that the fatigue cracks at rib-to-deck joints appear to be more critical within the deck plate than within the rib wall.

\section{Finite Element Analysis}

\subsection{Model}

Finite element models were developed to evaluate the effective notch stresses at weld toes and root of the rib-todeck joint. Fig. 5(a) shows the global model using the finite element analysis software ABAQUS (ABAQUS Inc. 2009). Test specimens were modeled by using linear elastic 3-D shell elements. A Young's modulus of $200 \mathrm{GPa}$ and a Poisson's ratio of 0.3 were assigned to the elastic material properties.

A submodel using solid elements, shown in Fig. 5(b), was then developed, taking the related boundary conditions from the global model, in order to evaluate the effective notch stresses at the toes and root of the weld.

Fig. 6 shows the details of this submodel. The global

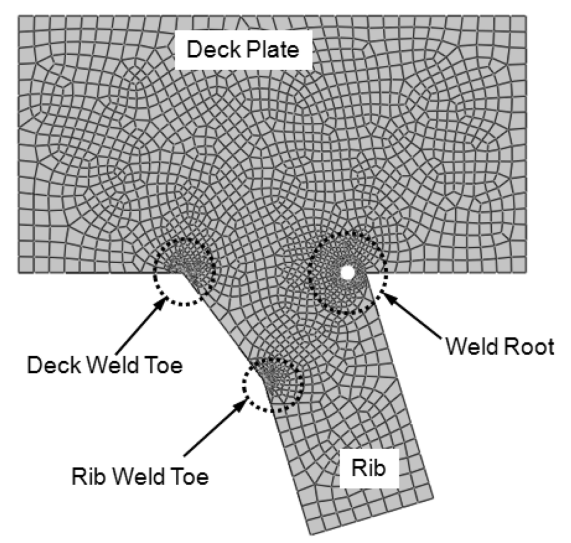

(a) Cross section

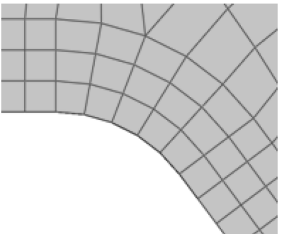

Deck Weld Toe

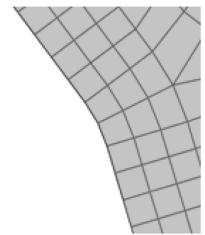

Rib Weld Toe (b) Weld toes

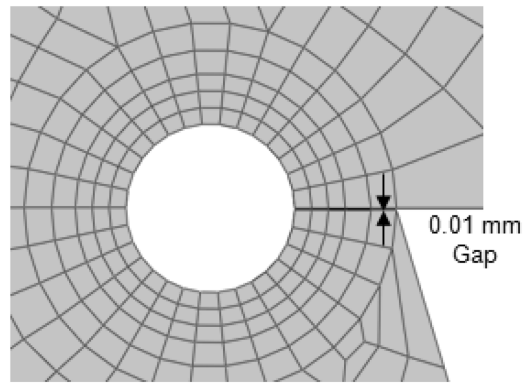

(c) Weld root

Fig. 6 Details of submodel

weld size in the model was determined based on the measurement of the tested specimens. A notch radius of 0.5 $\mathrm{mm}$, with element size of $0.1 \mathrm{~mm}$, were used for the model based on the recommendations in IIW (2007). A root gap of $0.01 \mathrm{~mm}$ between the rib and deck plate was assumed. Eighty percent weld penetration was modeled such that the tip of effective notch radius matches the root of the real notch. The same elastic material properties, as were used in the global model, were assigned.

\subsection{Effective notch stresses}

Fig. 7 shows the contours of the effective notch stresses on the cross section at midspan; Von-Mises stresses are used in this analysis. Comparing the stresses at the weld toes on bottom of deck plate and rib wall, about $80 \%$ higher stress is identified on the deck plate side. Compar- 


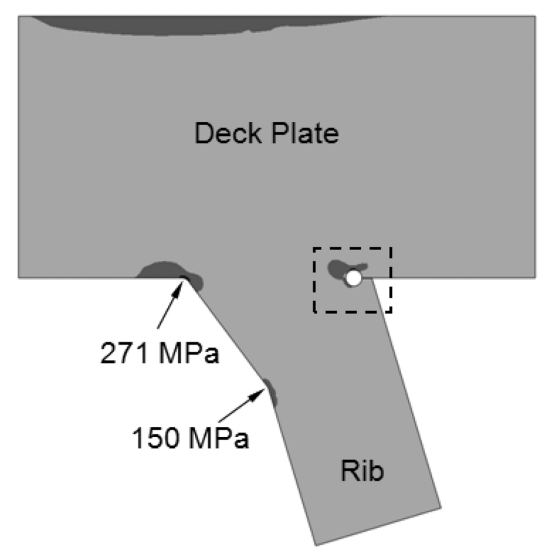

(a) at weld toes

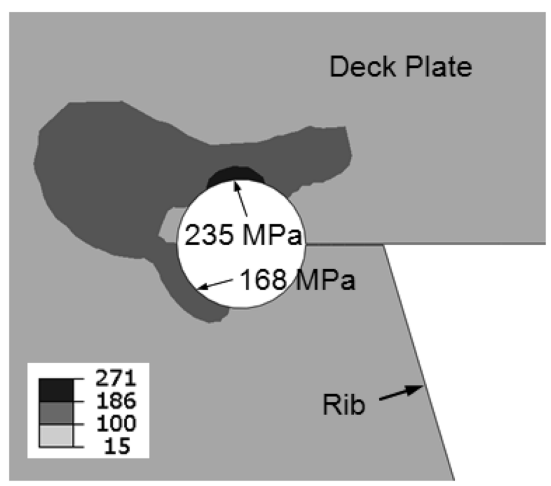

(b) at weld root

Fig. 7 Effective notch stresses

ing the stresses between the root and critical toe, about $15 \%$ higher stress is identified on the toe side.

\section{Correlation with Observed Crack Patterns in Fatigue Tests}

\subsection{Fatigue cracks at weld toe}

Fatigue test results showed that all of six cracks at the weld toe developed in the deck, not in the rib wall. This experimental finding on the crack pattern provides a good correlation with the numerical simulation in which about $80 \%$ higher effective notch stress was identified on the deck plate side.

Test results also showed that six cracks initiated from the weld toe, and only one crack initiated from the weld root. The dominant occurrence of cracks at the toe side is also consistent with the numerical simulation in which about $15 \%$ higher effective notch stress was identified on the toe side.

\subsection{Fatigue cracks at weld root}

It was observed from the test that one crack initiated from the weld root and propagated upward into the deck plate. As shown in Fig. 7(b), the maximum stress (235 MPa) occurs on the upper side of the root notch. The next highest stress (168 MPa) location is on the lower side of the notch. The higher notch stress on the upper side may indicate that cracks, when initiates at the weld root, are more likely to propagate through the deck plate, not through the weld metal. In contrast, if the lower side has a higher notch stress, cracks may be more likely to propagate through the weld metal. No such crack pattern, penetrating through the weld metal, was identified in the testing. The crack was observed to propagate into the deck plate.

\section{Conclusion}

Based on the applied loading pattern, the effective notch stress at the weld toe on bottom of deck plate was about $15 \%$ higher than that on the weld root. This gives an indication on the test results in which six among seven cracks occurred at the weld toe. The effective notch stress at the toe on the deck plate is about $80 \%$ higher than that on the rib; note that no cracks at the weld toe on the rib in the testing were observed.

Maximum effective notch stress at the weld root occurred on the upper side of the root notch, which indicates that cracks are more likely to propagate into the deck plate, not into the weld metal. This is also consistent with the observed crack pattern in which the crack from the root propagated upward into the deck plate. No such crack pattern, propagating into the weld metal, was observed in the testing. Therefore, effective notch stress approach provided a good correlation with the observed crack pattern in the fatigue test.

\section{References}

1. ABAQUS. (2009). ABAQUS Standard Users Manual, Version 6.9, ABAQUS Inc. Providence, RI.

2. IIW. (2007). "Recommendations for Fatigue Design of Welded Joints and Components," Hobbacher, A. (Ed), IIW Document XIII-2151r1-07/XV-1254r1-07, International Institute of Welding.

3. Miki, C. (2006). "Fatigue Damage in Orthotropic Steel Bridge Decks and Retrofit Works," International Journal of Steel Structures, KSSC, Vol. 6, No. 4, pp. 255-267.

4. Sim, H. B. and Uang, C. M. (2007). "Effects of Fabrication Procedures and Weld Melt-through on Fatigue Resistance of Orthotropic Steel Deck Welds," Report No. SSRP-07/13, Dept. of Structural Engineering, Univ. of California, San Diego.

5. Troitsky, M. S. (1987). Orthotropic Bridges, Theory and Design, Second Edition, The James F. Lincoln Arc Welding Foundation, Cleveland, $\mathrm{OH}$.

Received(April 17, 2012), Revised(June 15, 2012),

Accepted(June 20, 2012) 